\title{
Tunneling cracks in full scale wind turbine blade joints
}

Jørgensen, Jeppe Bjørn; Sørensen, Bent F.; Kildegaard, C.

\section{Published in:}

Engineering Fracture Mechanics

Link to article, DOI:

10.1016/j.engfracmech.2017.11.016

Publication date:

2018

Document Version

Peer reviewed version

Link back to DTU Orbit

Citation (APA):

Jørgensen, J. B., Sørensen, B. F., \& Kildegaard, C. (2018). Tunneling cracks in full scale wind turbine blade joints. Engineering Fracture Mechanics, 189, 361-376. https://doi.org/10.1016/j.engfracmech.2017.11.016

\section{General rights}

Copyright and moral rights for the publications made accessible in the public portal are retained by the authors and/or other copyright owners and it is a condition of accessing publications that users recognise and abide by the legal requirements associated with these rights.

- Users may download and print one copy of any publication from the public portal for the purpose of private study or research.

- You may not further distribute the material or use it for any profit-making activity or commercial gain

- You may freely distribute the URL identifying the publication in the public portal

If you believe that this document breaches copyright please contact us providing details, and we will remove access to the work immediately and investigate your claim. 


\title{
Tunneling cracks in full scale wind turbine blade joints
}

\author{
Jeppe B. Jørgensen ${ }^{\mathrm{a}, \mathrm{b}}$, Bent F. Sørensen ${ }^{\mathrm{b}}$, Casper Kildegaard ${ }^{\mathrm{a}}$ \\ ${ }^{a}$ LM Wind Power, Østre Alle 1, 6640 Lunderskov, Denmark. \\ ${ }^{b}$ The Technical University of Denmark, Dept. of Wind Energy, Frederiksborgvej 399, \\ 4000 Roskilde, Denmark.
}

\begin{abstract}
A novel approach is presented and used in a generic tunneling crack tool for the prediction of crack growth rates for tunneling cracks propagating across a bond-line in a wind turbine blade under high cyclic loadings.

In order to test and demonstrate the applicability of the tool, model predictions are compared with measured crack growth rates from a full scale blade fatigue test. The crack growth rates, measured for a several metre long section along the blade trailing-edge joint during the fatigue test, are found to be in-between the upper- and lower-bound predictions.
\end{abstract}

Keywords: Bonded joints, Fatigue crack growth, Residual stresses, Polymer matrix composites, Finite element analysis

Email address: jeppbj@dtu.dk (Jeppe B. Jørgensen) 


\section{Nomenclature}

a crack length

C Paris law coefficient

$d a / d N$ crack growth rate

$E_{1}, E_{2}$ Young's modulus (substrate, adhesive)

$\bar{E}_{1}, \bar{E}_{2}$ plane strain Young's modulus (substrate, adhesive)

$(E I)$ bending stiffness of DCB specimen arms

$f \quad$ non-dimensional function

$F \quad$ function that relates $\Delta K$ with $d a / d N$

$G_{s s} \quad$ mode-I steady-state energy release rate

$h_{1}, h_{2}$ thickness for sandwich (substrate, adhesive)

$h_{1}^{*}, h_{2}^{*}$ thickness for bi-layer (substrate, adhesive)

$\bar{h}_{2} \quad$ average thickness of adhesive in blade section

$J \quad J$-integral

$K \quad$ stress intensity factor

$L_{b} \quad$ blade length

$L_{c} \quad$ crack spacing

$\bar{L}_{c} \quad$ average crack spacing

$L_{r} \quad$ roller distance for DCB 


\begin{tabular}{|c|c|}
\hline$m$ & Paris law exponent \\
\hline$M$ & bending moment \\
\hline$M_{x x}$ & edgewise bending moment \\
\hline$N$ & cycles \\
\hline$P$ & load \\
\hline$q$ & non-dimensional function \\
\hline$r$ & radius \\
\hline$R$ & load $R$-ratio \\
\hline$t$ & width of cracked area for DCB \\
\hline$x, y, z$ & coordinates \\
\hline$\alpha$ & first Dundurs' parameter \\
\hline$\beta$ & second Dundurs' parameter \\
\hline$\delta_{\text {ext }}$ & extensometer opening \\
\hline$\delta_{c o d}$ & crack opening displacement profile \\
\hline$\epsilon_{T}, \epsilon_{y y}$ & strain (misfit, adhesive/substrate) \\
\hline$\zeta, \zeta_{*}$ & thickness ratio (sandwich, bi-layer) \\
\hline$\kappa$ & curvature of bi-layer \\
\hline$\nu_{1}, \nu_{2}$ & Poisson's ratio (substrate, adhesive) \\
\hline$\sigma_{m}$ & mechanical stress \\
\hline$\sigma_{r}$ & residual stress \\
\hline
\end{tabular}


$\sigma_{T} \quad$ misfit stress

$\sigma_{y y, 2} \quad$ stress in adhesive

$\Sigma, \Sigma_{*}$ stiffness ratio (sandwich, bi-layer)

CAD computer-aided design

DCB double cantilever beam

FE finite element

LEFM linear elastic fracture mechanics

VARTM vacuum-assisted-resin-transfer-moulding

\section{Introduction}

Full-scale structural blade testing is the main method used for testing the life-time performance of wind turbine blades and is commonly used for blade certification [1]. The main purposes of full-scale static blade testing are to test that new blade designs meet requirements and to gain insight into the failure mechanisms $[2,3,4,5,6,7]$. Publications of full-scale blade testing under cyclic loadings are limited due to confidentiality and the few testing laboratories that are actually able to perform the test [5]: DTU Wind Energy, LM Wind Power, Siemens Wind Power, Blaest (all in Denmark), CRES in Greece, WMC in Netherlands, NREL, LBR\&TF, WTTC (all in USA), NaREC in UK, Fraunhofer in Germany and SGS in China.

A wind turbine life-time is typically designed for 20 years or more [8, 9, 10, 11]. Thus, a wind turbine blade in operation is affected by cyclic loadings 
i.a. caused by gravity loads, see edge-wise bending moment, $M_{x x}$ in Figure 1. The adhesive joints are one of the critical structural details in large wind turbine blades. In particular, the trailing-edge is critical since it is located far from the elastic center of the blade and therefore experiences significantly higher strains, $\epsilon_{y y}$ when subject to edge-wise bending.

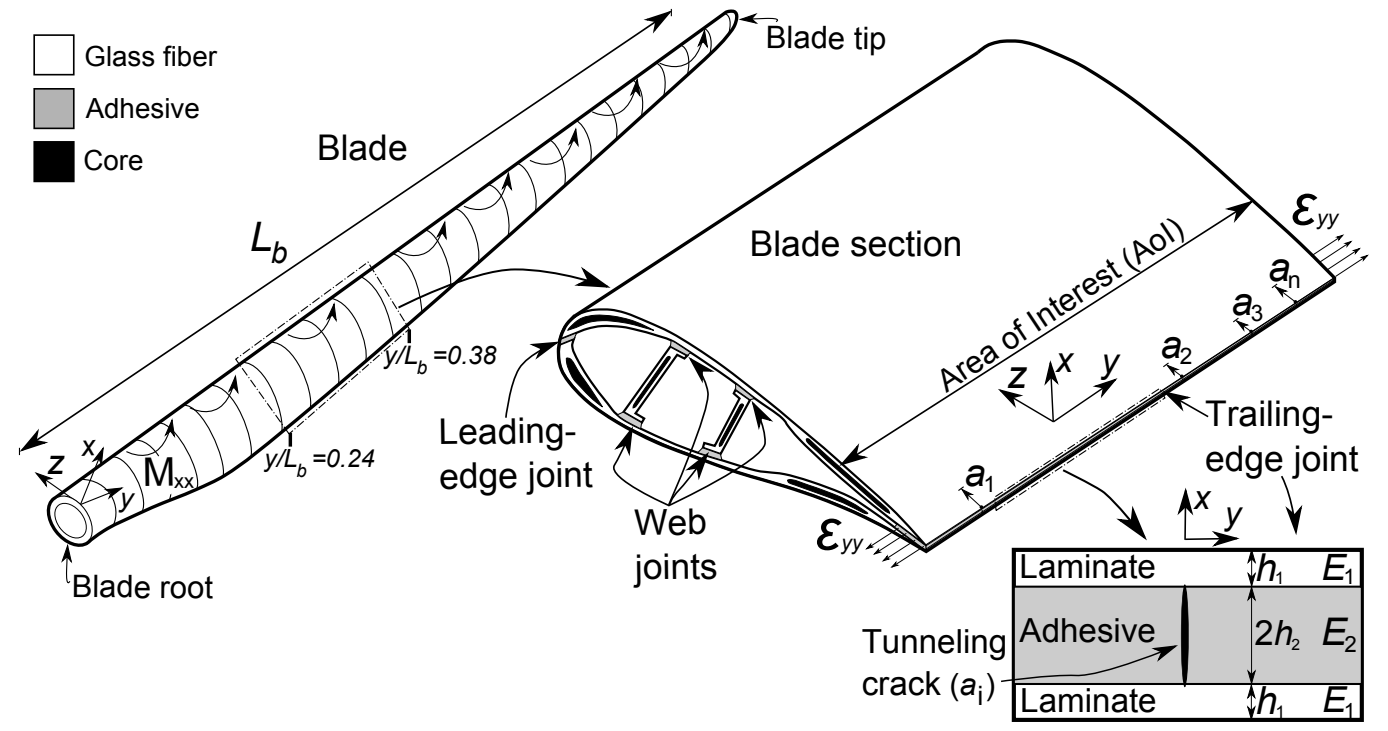

Figure 1: Blade with edge-wise bending moments, $M_{x x}$ distributed over blade length, $L_{b}$. Blade section includes web-, leading-edge-, and trailing-edge joints.

During excessive high cycle loading, tunneling cracks may initiate in the trailing-edge adhesive joint as shown in Figure 2, where a tunneling crack in the adhesive is encircled by red marker on the edge of the joint. The tunneling cracks propagate in the $z$-direction as shown by $a_{1}, a_{2}, \ldots, a_{n}$ in Figure 1. Each tunneling crack with length, $a_{i}$, has a unique configuration of laminate stiffness, $E_{1}$, adhesive stiffness, $E_{2}$, laminate thickness, $h_{1}$, adhesive thickness, $2 h_{2}$ and strain level, $\epsilon_{y y}$ dependent on specific location of the crack tip in the $y$ - $z$ plane. Note, the average adhesive thickness along the length 
of the blade section is denoted $2 \bar{h}_{2}$.

Ataya et al. [12] documented the presence of transverse cracks, of lengths $20 \mathrm{~mm}$ to $50 \mathrm{~mm}$, in trailing-edge joints on wind turbine blades operating in the field with working life ranging between $6.5 \times 10^{7}$ and $1.1 \times 10^{8}$ cycles. It was not documented how these transverse (tunneling) cracks initiated and developed. The traditional understanding of transverse cracking is that the cracks start from an edge-flaw and propagate across the adhesive layer. The adhesive is constrained by stiff laminates, primarily with uni-directional fibers, oriented in blade length, i.e. the $y$-direction in Figure 1. Thus, the tunneling crack in the brittle adhesive layer is constrained in-between laminates with higher stiffness and strength. Tunneling cracks propagating across a bond-line, loaded quasi-static or cyclic, are comparable with propagating off-axis matrix tunneling cracks in composite structures e.g. cross ply laminates $[13,14,15,16,17,18,19,20,21]$.

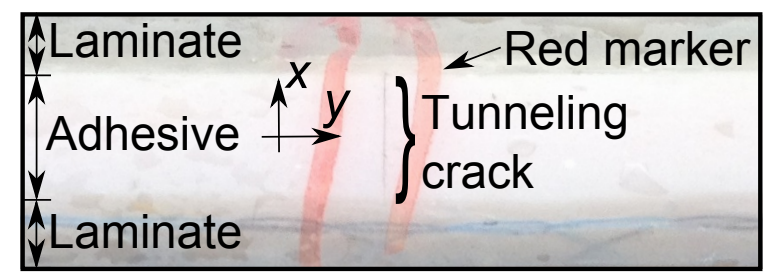

Figure 2: Tunneling crack identified in the trailing-edge joint of a full scale test blade.

Tunneling cracks have been modelled extensively through the last three decades using linear elastic fracture mechanics (LEFM) [22, 23, 24, 25, 19, 26, 27]. From a modelling perspective, this cracking mechanism is closely related to channeling cracks in thin films [28, 29, 30, 31, 32]. One of the first models of a single tunneling crack embedded in-between thick substrates were 
developed using 2D finite element (FE) modelling and LEFM [22, 23, 24]. 3D FE models were used for transient modelling of channeling/tunneling cracks since the crack length must reach a certain length for the crack to become steady-state $[33,34,35,26]$. It is well known [36, 37] that the stress field of bi-material problems with stresses as boundary conditions (not displacement boundary conditions) depends on only two (not three $E_{1} / E_{2}, \nu_{1}, \nu_{2}$ ) nondimensional elastic parameters (Dundurs' parameters):

$$
\alpha=\frac{\bar{E}_{1}-\bar{E}_{2}}{\bar{E}_{1}+\bar{E}_{2}} \quad \text { and } \quad \beta=\frac{\bar{E}_{1} \frac{\left(1-2 \nu_{2}\right)}{2\left(1-\nu_{2}\right)}-\bar{E}_{2} \frac{\left(1-2 \nu_{1}\right)}{2\left(1-\nu_{1}\right)}}{\bar{E}_{1}+\bar{E}_{2}}
$$

where for plane strain $\bar{E}=E /\left(1-\nu^{2}\right) . \nu_{1}$ and $\nu_{2}$ are the Poisson's ratio of the substrate and adhesive, respectively. In order to apply Dundurs' parameters, it is also a prerequisite that the materials are isotropic, linear-elastic and deformations are planar i.e. either plane strain or plane stress $[38,36]$. These prerequisites are satisfied for the sandwich in Figure 2 if the adhesive and laminates are assumed isotropic, linear-elastic and the tunneling crack has reached a certain length from the edge (in $z$-direction) i.e. steady-state.

Nucleation and propagation of tunneling cracks in the adhesive layer is the first mode of damage of the joint and would not represent catastrophic failure of the blade, or even any significant loss in performance. However, if the tunneling cracks were to initiate delaminations in the laminates or large debonds at the adhesive-laminate interface, this would be far more critical. Tracking and prediction of tunneling cracks propagation are important in order to detect the early stage of damage and to quantify the level of damage before it transforms into a more critical state such as delamination. A safe and conservative joint design is thus designed against the propagation of a 
tunneling crack across the bond-line. Therefore, it is relevant to develop rigorous tools for the prediction of tunneling crack propagation in a full scale wind turbine blade joint, especially under cyclic loading.

\section{Approach and problem definition}

In this paper a novel approach is presented for the prediction of crack growth rates of tunneling cracks in a wind turbine blade joint. The approach includes a generic tunneling crack tool that is exemplified and tested on a trailing-edge joint in a full scale wind turbine blade fatigue test.

The approach enables prediction of crack growth rates for tunneling cracks in adhesive bond-lines, e.g. for wind turbine blade joints, based on information of the tunneling crack state (geometry, start-crack-length, loads and constitutive properties). Crack growth rates (Paris law) for the adhesive are measured by a double cantilever beam (DCB) specimen in laboratory, where the adhesive is loaded cyclic in mode-I $[39,40]$. This is elaborated in Section 3.

In adhesive bonded joints residual stresses might develop in the adhesive during the manufacturing process i.a. attributed chemical shrinkage of the adhesive and mismatch in coefficient of thermal expansion between adhesive and laminate. Generally, residual stresses originate from misfits between different material regions or phases [41, 42, 43]. The misfit stress, $\sigma_{T}$, (defined in Section 4) is determined using measured curvature of a bi-layer specimen in the laboratory. The misfit stress is converted to a residual stress, $\sigma_{r}$, in the adhesive, using an analytical sandwich model, to account for local thicknesses and stiffnesses in the blade according to specific crack locations $(y, z)$. It is 
advantageous to express the residual stress through a misfit stress since the description of the misfit stress only depends on the adhesive properties and is independent of the application (e.g. thicknesses), whereas the residual stress is application dependent. Thus, the use of the misfit stress is convenient since the misfit stress can be scaled through a non-dimensional function, $q$, to give the residual stress for the application of interest [44]. This is presented in details in Section 4.

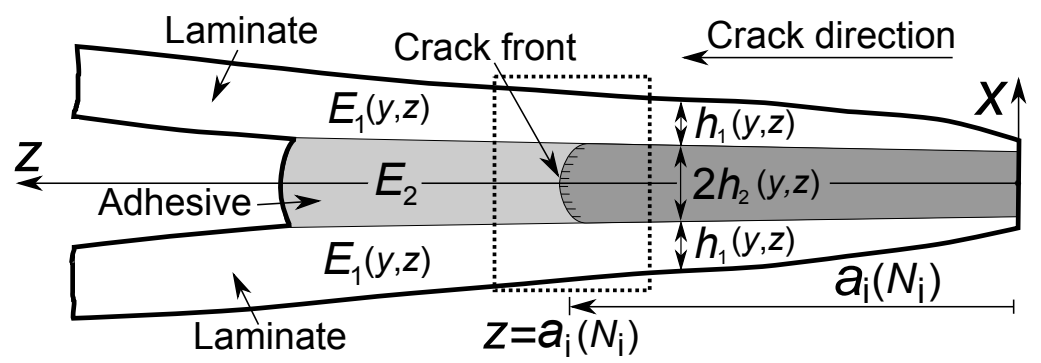

Figure 3: Tunneling crack in trailing-edge joint. The dashed square at position $z=a_{i}\left(N_{i}\right)$ shows the crack configuration that is analysed using a plane strain condition and LEFM modelling.

The tunneling crack tool takes the local -stiffness and -geometry input from blade models/measurements, shown in Figure 3, including mechanical stress, $\sigma_{m}$, and residual stress, $\sigma_{r}$, in the adhesive. In the real structural blade application, these many parameters dependence on crack tip location $(y, z)$ for each tunneling crack complicates the modelling significantly. Combining these inputs, using LEFM and a plane strain assumption, enables determination of the mode-I steady-state energy release rate, $G_{s s}$ for a single 
isolated tunneling crack [24]:

$$
G_{s s}(y, z)=\frac{\left[\sigma_{m}(y)+\sigma_{r}(y, z)\right]^{2} 2 h_{2}(y, z)}{\bar{E}_{2}} f\left[\alpha(y, z), \beta(y, z), h_{1}(y, z) / h_{2}(y, z)\right]
$$

where subscripts 1 and 2 refer to substrate and adhesive, respectively. $f$ is a non-dimensional function that will be determined in the present paper by 2D finite element simulations. Since the loading is cyclic, $G_{s s}^{\min }$ and $G_{s s}^{\max }$ are converted to a cyclic stress intensity factor range, $\Delta K$ using an analytical model as elaborated in Section 5. Combining the tunneling crack modelling results with the measured residual stresses and the measured Paris law for the adhesive, gives the prediction of the crack growth rate for each tunneling crack along the blade section. The steps of the approach, presented in Figure 4, are summarized:

(i) DCB: Double cantilever beam specimen fatigue tested in laboratory to measure Paris law $(d a / d N, \Delta K)$ for a mode-I crack in the adhesive.

(ii) Bi-layer: Residual stress $\left(\sigma_{r}\right)$ determination in the adhesive of the joint using misfit stress $\left(\sigma_{T}\right)$ that is determined by measuring the curvature of bi-layer specimens.

(iii) Blade: Characterization of geometry $\left(h_{1}, 2 h_{2}\right)$, crack length for each crack $\left(a_{i}\right)$, cycles for each crack $\left(N_{i}\right)$, constitutive properties $\left(E_{1}, E_{2}, \nu_{1}, \nu_{2}\right)$, and mechanical stresses $\left(\sigma_{m}^{\min }, \sigma_{m}^{\max }\right)$ from blade inspection/model, CAD model, aero/FE model or similar.

(iv) Modelling: Tunneling cracks modelled using finite elements to determine $\Delta K_{i}$ as a function of blade geometry/properties, mechanical stress, and residual stress $\left(h_{1}, 2 h_{2}, E_{1}, E_{2}, \nu_{1}, \nu_{2}, \Delta \sigma_{m}, \sigma_{r}\right)$ for each tunneling crack configuration $\left(a_{i}, N_{i}\right)$ dependent on location $(y, z)$. 
(v) Blade prediction: Prediction of $d a_{i} / d N_{i}$ for each tunneling crack in the blade using $\Delta K_{i}$ from tunneling crack model and Paris law $(d a / d N)$ for the adhesive that is measured by a DCB test in laboratory. Note, $F$ is a function that relates $\Delta K$ with $d a / d N$.

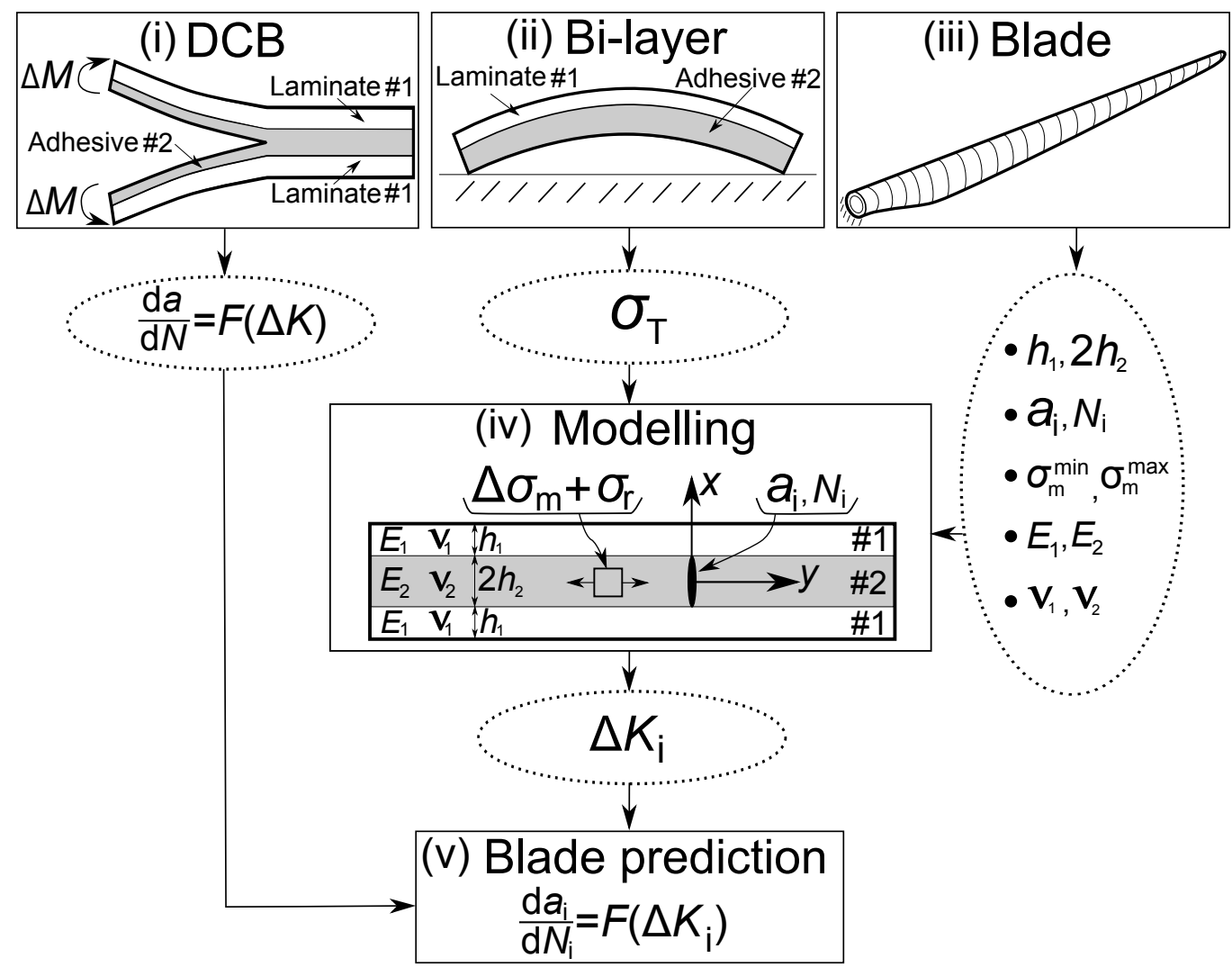

Figure 4: Approach for prediction of crack growth rate for each tunneling crack in a wind turbine blade joint. Step (i) and (ii) are material characterisation whereas step (iii), (iv) and $(v)$ are repeated for each crack with length, $a_{i}$.

The properties of the adhesive are characterized in step $(i)$ and $(i i)$, whereas step $(i i i),(i v)$ and $(v)$ are repeated for crack number $i=1$ to $i=n$ according to each cracks specific location $(y, z)$ in the blade. In order to test 

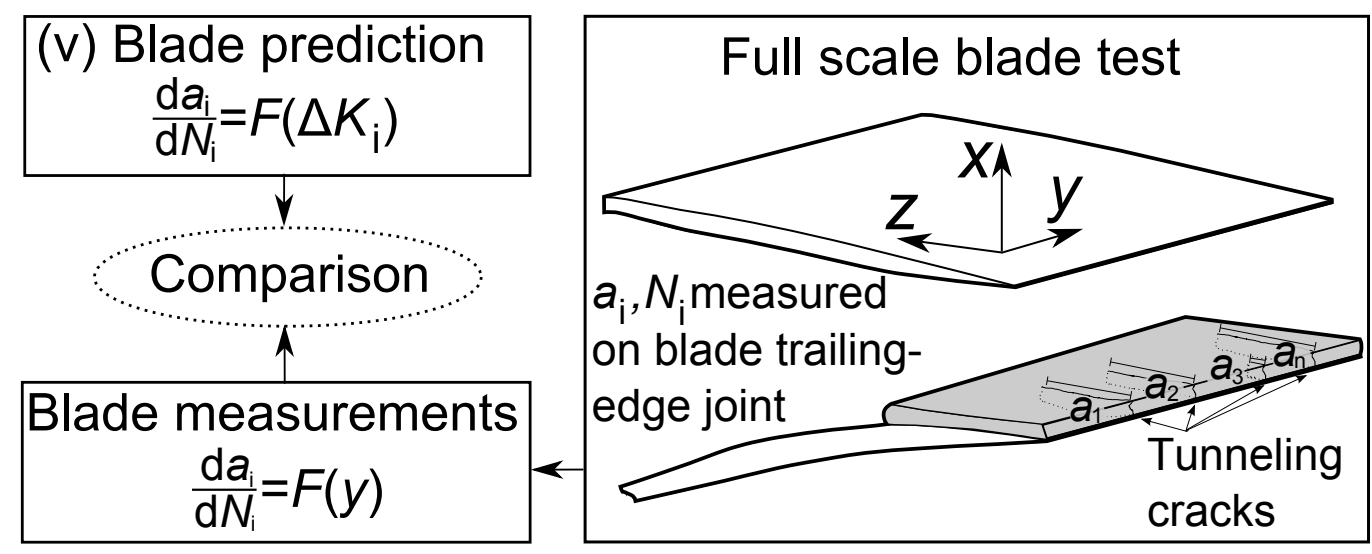

Figure 5: Experimental demonstration for tunneling cracks in a trailing-edge joint. The prediction of crack growth rate for each tunneling crack is tested and compared with the actual measurement on a generic research blade.

the accuracy of the proposed approach, the predicted crack growth rates are compared with crack growth rates measured on a generic research blade as shown in Figure 5. The equations and procedures used for the approach are implemented in a Python program using primarily the Numpy (numerical) and Pandas (data analysis) packages [45, 46]. Thus, it is easy to change the loads, the number of cracks etc. if predictions on other joints in the blade are desired.

\section{Theoretical framework: DCB tests to measure Paris law for the} adhesive

The DCB specimen is tested by applying a cyclic bending moment to determine the mode-I Paris law for the adhesive using the test setup presented in Figure 6 . The $J$-integral for the moment-loaded DCB specimen is [47, 48]:

$$
J=\frac{M^{2}}{(E I) t}
$$


where $M=P L_{r}$ and $t$ is the width of the cracked area. $P$ is the measured load and $L_{r}$ is the outer distance between rollers according to Figure 6 . The bending stiffness, EI is determined by a layered model of the laminate and adhesive using classical laminate theory [49]. The mode-I stress intensity factor for an isotropic material can be related to the mode-I energy release rate using the well-known Irwin relation [50]:

$$
K=\sqrt{G \bar{E}_{2}}
$$

$\Delta K$ can be related to fatigue crack growth through the empirical ParisErdogan law [39, 40]:

$$
d a / d N=C(\Delta K)^{m}
$$

The parameters in the power law, $C$ and $m$ are material constants that are determined using a curve fit to actual test data. The use of the Paris law requires that the linear-elastic fracture mechanics assumptions are satisfied meaning that the material must be linear elastic, isotropic, and the fracture process zone must be small in comparison with the other specimen dimensions. Note, Paris law is an empirical relation rather than theoretically based [51].

The DCB specimen with side-grooves, shown in Figure 6, is designed based on initial experiments, which shows that the crack grows to the adhesivelaminate interface if no side-grooves are present. The test setup, presented in Figure 6, has some advantages: 1) energy release rate being independent of crack-length so that crack growth is stable under displacement (rotational) control, 2) easy analytical evaluation of the $J$-integral. Furthermore, a full range of mode mixities can be tested from pure mode-I to nearly pure 


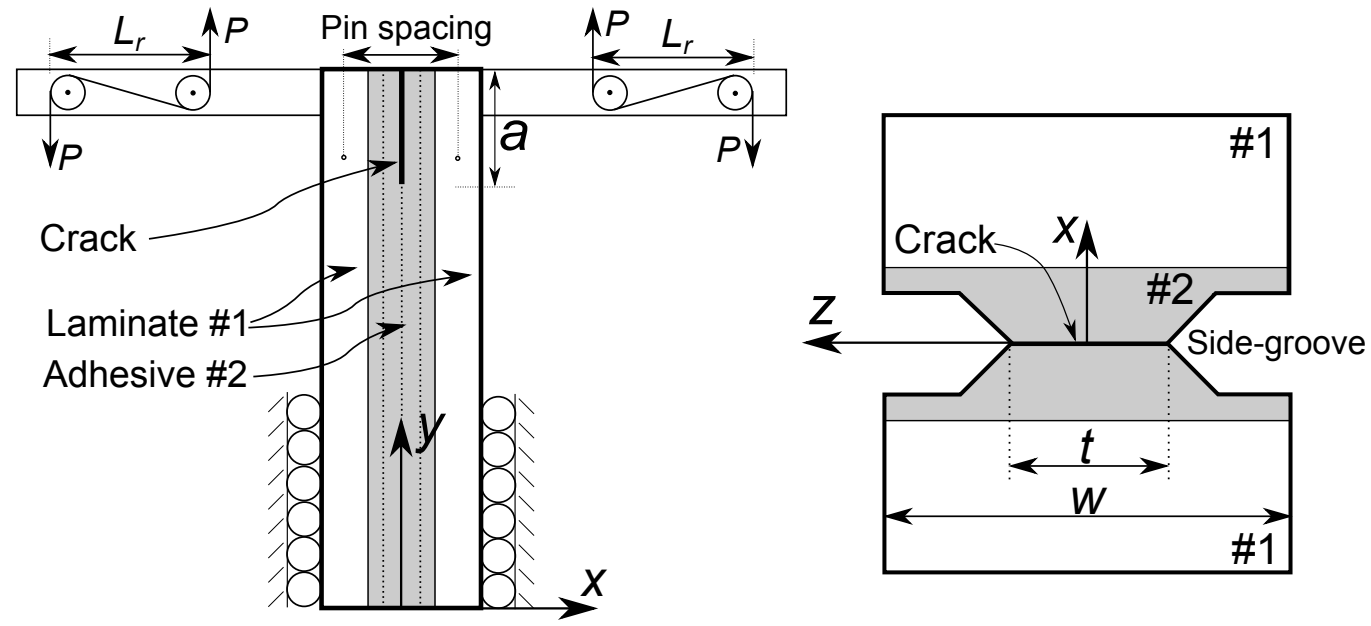

Figure 6: DCB specimen loaded cyclic with even bending moments in mode-I.

mode-II. For the present work and purpose the setup is kept in mode-I since the tunneling cracks in the adhesive, which is assumed isotropic, propagates under mode-I conditions.

For experiments conducted under displacement control, the magnitude of the moment, $M$ decreases as the crack length increases. Thus, a test in displacement control gives information of crack growth rate for the full range of load levels using only a single test specimen. Therefore, in the present study the DCB specimen is loaded cyclic using a constant range of extensometer opening, $\Delta \delta_{\text {ext }}$ since it is desired to measure the full Paris law.

\section{Theoretical framework: Measuring residual stresses using bi- layer specimen}

The residual normal stress, $\sigma_{r}$, e.g. in a symmetric sandwich far from edges as shown in Figure 7, can be related to the misfit stress, $\sigma_{T}$ through a 
non-dimensional function, $q[44]$ :

$$
\sigma_{r}=q \sigma_{T}
$$

where $\sigma_{T}$ is defined as the stress induced in an infinitely thin film adhered to an infinitely thick substrate in a bi-layer material. $q$ is a non-dimensional function accounting for e.g. geometry and elastic properties. The misfit stress cannot be predicted by modelling - it must be measured experimentally [44] unless the mechanism of inelastic strain is known and modelled.

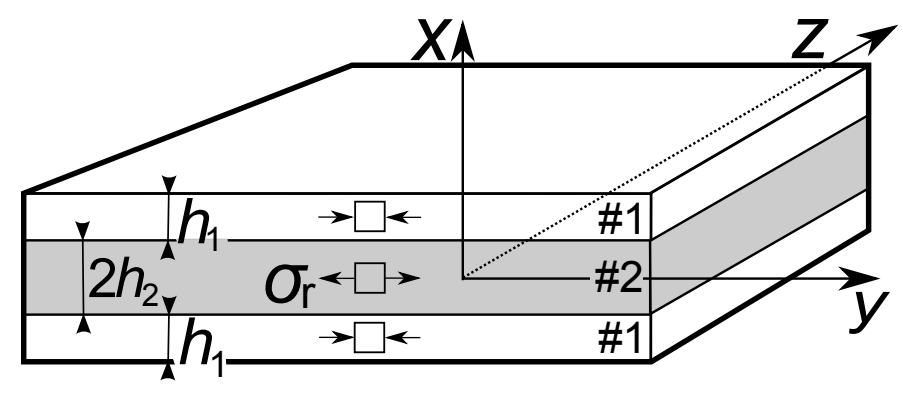

Figure 7: Sandwich specimen used for residual stress modelling.

The misfit stress can be measured using the bi-layer specimen shown in Figure $8[44,52,53]$. The curvature, $\kappa$ is determined by fitting a circle to a number of points measured on top of the surface of the curved beam. The radius of the fitted circle, determined using a least square fit to the measured points along the curved surface, expresses the curvature through the radius, $r$ as; $\kappa=1 / r$. The misfit stress, $\sigma_{T}$ can then be determined by [44]:

$$
\sigma_{T}=\frac{\left(\sum_{*} \zeta_{*}^{2}-1\right)^{2}+4 \sum_{*} \zeta_{*}\left(1+\zeta_{*}\right)^{2}}{6 \zeta_{*}\left(1+\zeta_{*}\right)}\left[\frac{E_{2} h_{2}^{*} \kappa}{\left(1-\nu_{2}\right)}\right]
$$

where $\sum_{*}=\frac{E_{1} /\left(1-\nu_{1}\right)}{E_{2} /\left(1-\nu_{2}\right)}$ and $\zeta_{*}=h_{1}^{*} / h_{2}^{*}$ according to Figure 8 for the bi-layer specimen. 


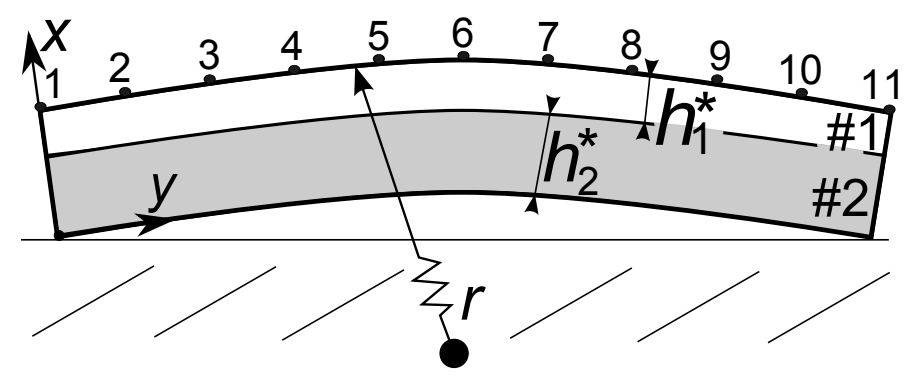

Figure 8: Curvature specimen including positions for measuring beam height.

Knowing $\sigma_{T}$, the stress in the adhesive of the sandwich specimen, shown in Figure 7, can be derived by equilibrium considerations (perfect bonding between the substrates and the adhesive layer), and by Hooke's law in plane stress (in the $x$-direction):

$$
\sigma_{r}=\frac{-\sigma_{T}}{\sum+\frac{1}{\zeta}}
$$

where $\sum=\frac{E_{1} /\left(1-\nu_{1}\right)}{E_{2} /\left(1-\nu_{2}\right)}$ and $\zeta=h_{1} / h_{2}$ according to Figure 7 for the sandwich specimen. The energy release rate of the tunneling crack in the sandwich specimen can be expressed as:

$$
G_{s s}=\left(\sigma_{m}+\sigma_{r}\right)^{2} \frac{2 h_{2}}{\bar{E}_{2}} f\left(\alpha, \beta, h_{1} / h_{2}\right)=\left(\sigma_{m}+\frac{-\sigma_{T}}{\sum+\frac{1}{\zeta}}\right)^{2} \frac{2 h_{2}}{\bar{E}_{2}} f\left(\alpha, \beta, h_{1} / h_{2}\right)
$$

where $f\left(\alpha, \beta, h_{1} / h_{2}\right)$ is determined in the next section.

\section{Theoretical framework: Modelling of tunneling cracks}

The steady-state energy release rate of an isolated tunneling crack can be expressed using a non-dimensional function, $f$ to account for stiffness and thickness of the materials [24]:

$$
\frac{G_{s s} \bar{E}_{2}}{\sigma_{y y, 2}^{2} 2 h_{2}}=f\left(\alpha, \beta, h_{1} / h_{2}\right)
$$


where the effective stress in the adhesive remote from the crack is designated $\sigma_{y y, 2}$. For simplicity, it is assumed that Poisson's ratio for substrates and adhesive are similar, $\nu_{1}=\nu_{2}=1 / 3$, leading to $\beta=\alpha / 4$. The steady-state energy release rate, which is constant along the entire tunneling crack front, is determined by $[22,24]$ :

$$
G_{s s}=\frac{1}{2} \frac{\sigma_{y y, 2}}{2 h_{2}} \int_{-h_{2}}^{+h_{2}} \delta_{c o d}(x) d x
$$

where $\delta_{\text {cod }}(x)$ is the crack opening displacement profile for the plane strain crack, which is determined by FE modelling. Trapezoidal integration is applied to evaluate the integral numerically.

The results from the tunneling crack bi-material FE model, simulated in Abaqus CAE 6.14 (Dassault Systemes) with eight-noded plane strain elements, are compared with the results of Ho and Suo [24] for a thickness ratio of $h_{1} / h_{2}=2.0$ as shown in Figure 9 .

The difference between the FE model results and those of Ho and Suo [24] are less than $2 \%$. As the stiffness and thickness of the substrates increase, $f\left(\alpha, \beta, h_{1} / h_{2}\right)$ becomes smaller. This is in agreement with the conventional models $[23,24,27]$. Different thickness ratio, $h_{1} / h_{2}$ are modelled hence $f\left(\alpha, \beta, h_{1} / h_{2}\right)$ for tunneling cracks at different locations can be determined. Figure 9 is the main theoretical result and the relevant stiffness ratio for typical wind turbine blade joints is large as highlighted with the dashed square $(0.7 \leq \alpha \leq 0.9)$.

The anisotropy of the glass fiber laminates is assumed negligible since it is assumed that the high in-plane laminate stiffness of the uni-directional fibers in the $y$-direction is the main constraint to prevent the tunneling crack propagation [27]. $\Delta K$ for an isotropic material can be related to $\Delta G_{s s}$ in 


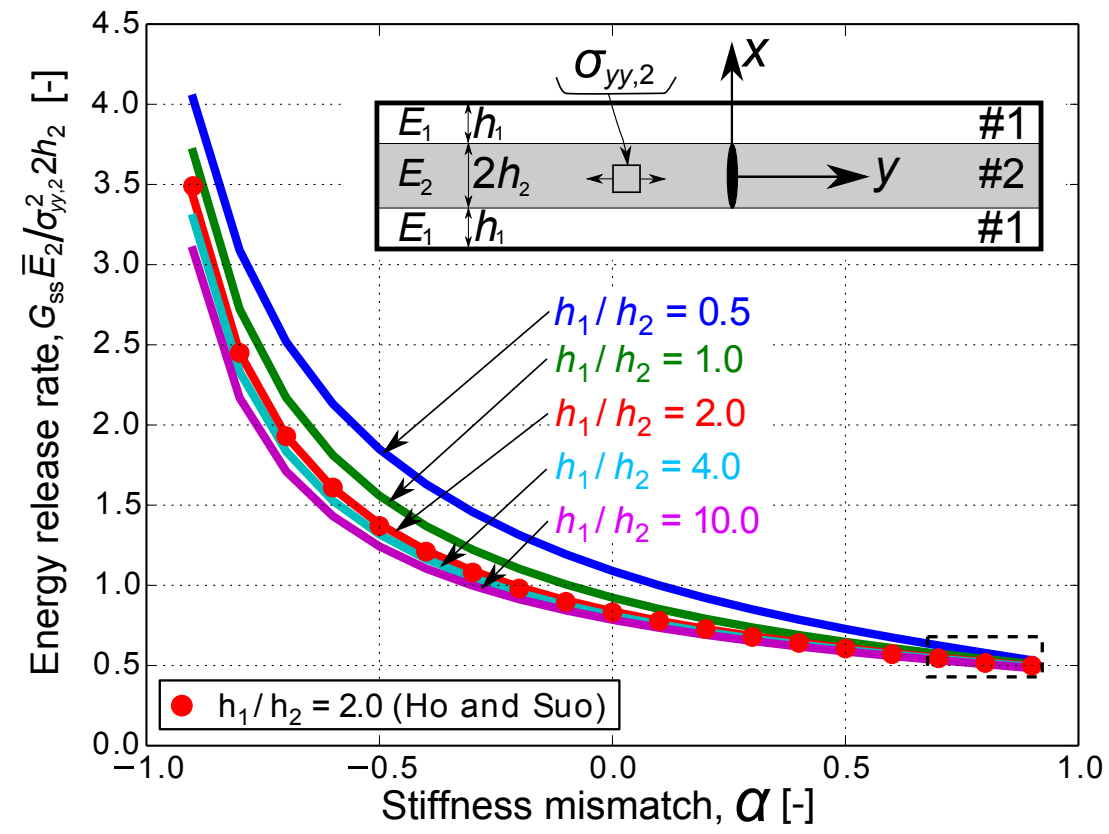

Figure 9: Results from tunneling crack bi-layer FE model and comparison with the model by Ho and Suo [24] for $h_{1} / h_{2}=2.0$ and $\beta=\alpha / 4$. 
mode-I using the Irwin relation $[19,50,51]$ :

$$
\Delta K=\sqrt{G_{s s}^{\max } \bar{E}_{2}}-\sqrt{G_{s s}^{\min } \bar{E}_{2}}=\Delta \sigma_{y y, 2} \sqrt{2 h_{2} f\left(\alpha, \beta, h_{1} / h_{2}\right)}
$$

that is applicable for tension-tension loading where the load $R$-ratio ( $R=$ $\left.\sigma^{\min } / \sigma^{\max }\right)$ is $0 \leq R<1$. However, for tension-compression loading where $R<0$, equation 12 reduces to:

$$
\Delta K=\sqrt{G_{s s}^{\max } \bar{E}_{2}}=\sigma_{y y, 2}^{\max } \sqrt{2 h_{2} f\left(\alpha, \beta, h_{1} / h_{2}\right)}
$$

For compression-compression loading with $R>1$, the stress intensity factor range becomes zero i.e. $\Delta K=0$. With the coefficient $C$ and exponent $m$ determined earlier from the DCB test, the crack growth rate $(d a / d N)$ of each crack can be determined from equation 5 . The stress range can be expressed as a function of load $R$-ratio, and residual stress $\left(\sigma_{r}\right)$ can be added to the mechanical stresses $\left(\sigma_{m}^{\min }, \sigma_{m}^{\max }\right)$ as shown in Figure 10.
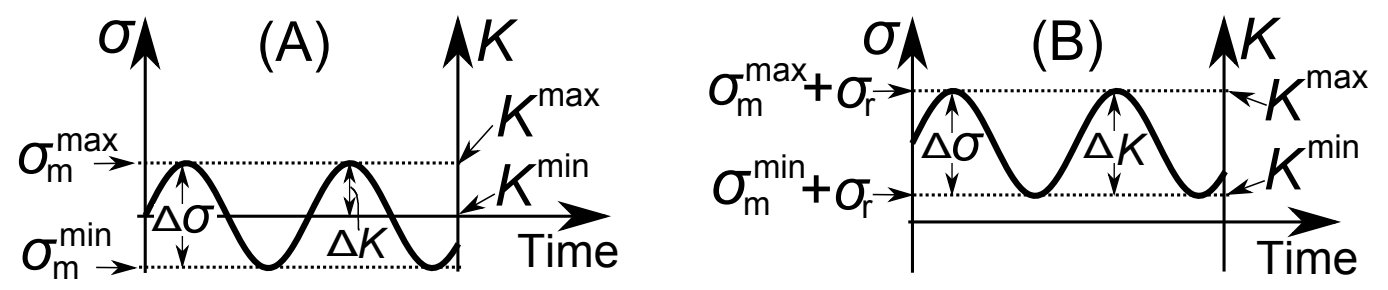

Figure 10: Definition of $\sigma_{m}^{\min }, \sigma_{m}^{\max }, \Delta \sigma, K^{\min }, K^{\max }$ and $\Delta K$ including a schematic illustration of how $\Delta K$ depends on the $R$-ratio. (A) with $R=-1$, and (B) with $0 \leq R<1$.

For negative $R$-ratio $(R<0)$ a part of the stress cycle is negative hence causing crack closure. In that case, only the positive part of the stress cycle is used in the computation of $\Delta K$ as illustrated in Figure 10. For the example in Figure 10, for the same applied stress range, $\Delta K$ is doubled if $R$-ratio increases from $R=-1$ to $0 \leq R<1$. Thus, Figure 10 illustrates the effect of increasing residual stresses on $R$-ratio and $\Delta K$. 


\section{Experimental demonstration: Test of full scale research blade}

A generic full scale research blade, with length of more than $40 \mathrm{~m}$, was manufactured and tested for approx. 5 million cycles in edge-wise direction with high loads. This corresponds to a full-life fatigue test. Hereafter, the blade was further tested with higher edge-wise cyclic loadings for approx. 1 million cycles, i.e. tested with loads beyond design limits to initiate tunneling cracks. The trailing-edge were loaded in tension-compression fatigue by a load $R$-ratio of $R=-1$ during the tests. It is unknown when the tunneling cracks initiated, but it was observed and documented that the tunneling cracks propagated through the second test with loadings higher than typical design loads. The experiment was paused 5 times, where the trailing-edge was inspected for cracks and the crack lengths were measured.

The outer trailing-edge thicknesses are measured at four locations (A, B, C, D) in $z$-direction for each meter along the blade length $(y)$, see Figure 11. The outer thickness measurements are used in combination with the laminate layup from a blade model to determine the actual adhesive thickness for each measurement.

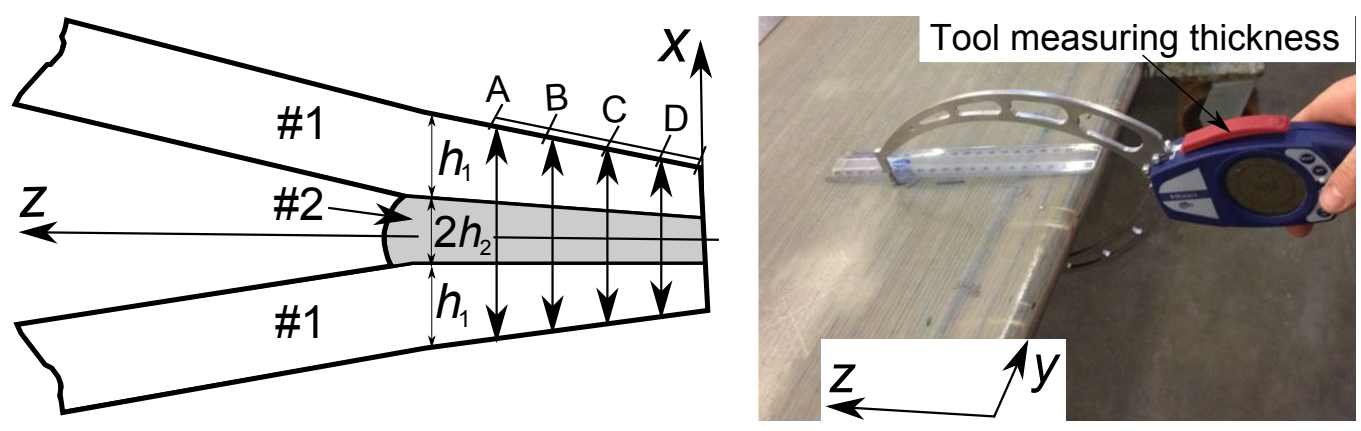

Figure 11: Thickness measurement of the trailing-edge joint at four points for each section. 
The stiffness and thickness of the laminates near each crack tip depends on the position in both $y$ - and $z$-directions as a result of the ply drops in both transverse- and longitudinal blade directions, see Figure 3, Figure 12 and Figure 13. The points in Figure 12 near $y / L_{b}=0.28$ and $y / L_{b}=0.32$ are not outliers. They are a result of large crack lengths hence the crack tip reach a location where the laminates are thicker, see also Figure 3 and Figure 18.

The average substrate-to-adhesive stiffness ratio, $\alpha$ at each crack position, presented in Figure 13, is determined using linear interpolation $(y, z)$. The number of uni-directional plies is dominant hence the average stiffness is simply a small reduction of the uni-directional ply stiffness due to some biaxial layers surrounding the uni-directional plies. The exact laminate and adhesive properties in the generic research blade are confidential.

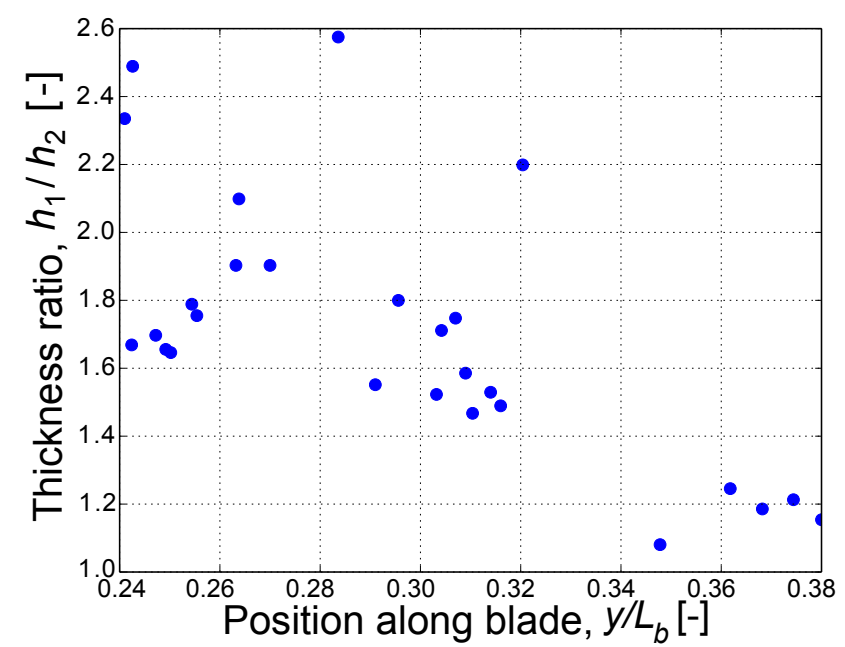

Figure 12: Laminate-adhesive thickness ratio determined at each tunneling crack position along blade length.

The strain range, $\Delta \epsilon_{y y}\left(=\epsilon_{y y}^{\max }-\epsilon_{y y}^{\min }\right)$ is measured using strain gauges 
located at every second meter along the blade length $(y)$. Variations of strains across the width of the trailing-edge joint $(z)$ are insignificant since the trailing-edge bond-line width is small compared with the distance from the elastic center of the blade to the trailing-edge location. The measured strains are post-processed through a "Rain-flow count algorithm" and sorted into bins dependent on the strain range magnitude [54]. The individual strain ranges are counted for each bin. The mechanical stress range, $\Delta \sigma_{m}$ in the adhesive is determined using Hooke's law and a plane strain assumption in the $y$-direction of the blade:

$$
\Delta \sigma_{m}=\bar{E}_{2} \Delta \epsilon_{y y}
$$

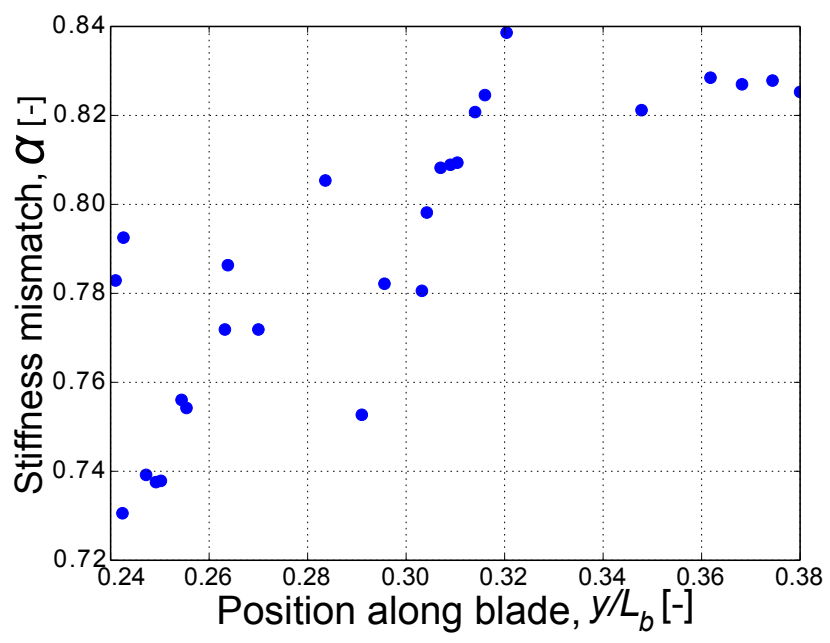

Figure 13: Laminate-adhesive stiffness mismatch determined at each tunneling crack position along blade length. 


\section{Experimental demonstration: DCB tests to determine Paris law for the adhesive}

Two laminates of glass fiber reinforced polyester are cast using vacuumassisted-resin-transfer-moulding (VARTM). The laminates are post cured and placed in a fixture where a vinylester adhesive is injected to bond the two laminates. Subsequently, the adhesive and laminate are post cured and cut into specimens. The side-grooves are $\mathrm{CNC}$ machined to meet the design in Figure 6. The adhesive and laminates are manufactured under laboratory conditions, but the exact properties are confidential.

An extensometer is attached to pins mounted on each beam as shown in Figure 6 to measure the extensometer opening. A servo-hydraulic cylinder applies the load, $P$ to the wires that are attached to two arms on the sides of the DCB specimen hence a pure bending moment is applied cyclic [55]. The end of each cable is attached to a load cell that measures the load, $P$ on each wire individually. Load frequency is set to $3 \mathrm{~Hz}$ and mode mixity to 0 degree using same arm length, $L_{r}$ as shown in Figure 6 . The $R$-ratio is varied between $R \approx 0.3$ and $R \approx 0.5$, which is also the $R$-ratio in the section of the blade joint when including residual stresses in the adhesive. Images are captured at adequate intervals following a log-scale. The crack length, $a$ is measured on the images with help from a program implemented in Python $[45,46]$.

The DCB test is controlled by the extensometer opening, $\delta_{\text {ext }}$. A fixed value of $\delta_{e x t}^{\min }$ and $\delta_{e x t}^{\max }$ is applied in the duration of the DCB test to maintain a constant $\Delta \delta_{e x t}$. Thus, as the crack grows (increasing $a$ ), the measured moment range, $\Delta M$ decreases and a series of $\Delta K$ values can be computed 
by equation 3, equation 4 and the first part of equation 12 .

Before starting the cyclic test, a static pre-test is performed to create a sharp start-crack; a clamp is mounted on the specimen to constrain the crack from propagating too long and a static moment is applied monotonic until a sharp pre-crack is formed. The clamp is removed and the specimen is now prepared for the cyclic loaded tests. The subsequent cyclic loaded tests on the same specimen continues without further static tests.

The measured Paris laws for the adhesive are presented in Figure 14. The Paris law parameters are determined by a least square fit to the measured data points in the log-log space $(\Delta K, d a / d N)$ on the form given by equation 5. The best fit in Figure 14 is used to determine parameters $C$ and $m$. The upper- and lower fit gives the upper- and lower bounds for $d a / d N$ as shown in Figure 14 by the dashed and dotted lines, respectively.

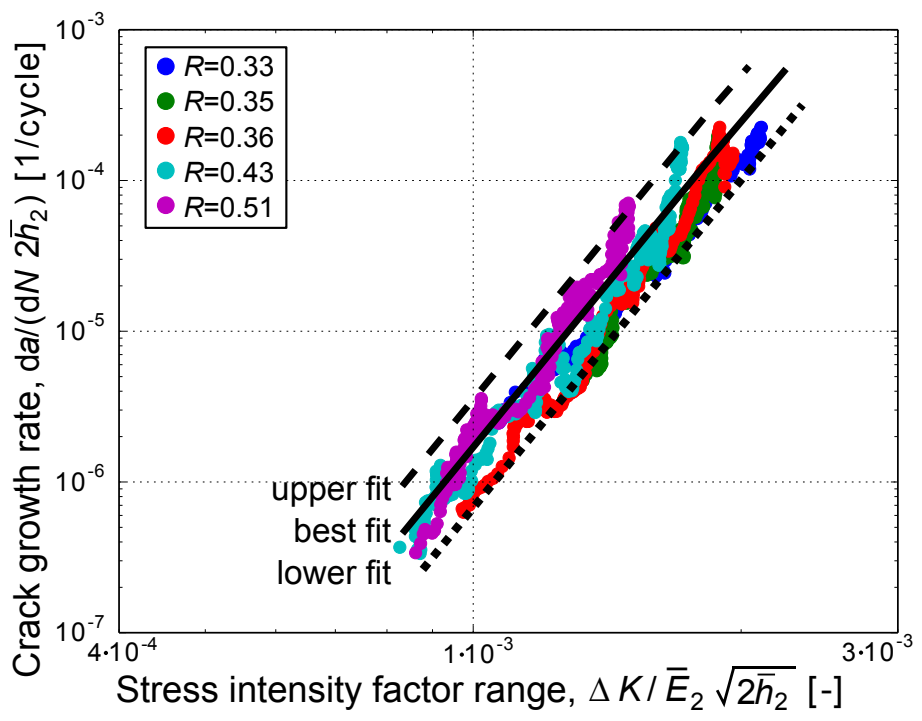

Figure 14: Cyclic loaded DCB test for adhesive including Paris law best fit. The axes are normalised by the average thickness of the adhesive measured on the blade section, $2 \bar{h}_{2}$. 
Some $R$-ratio effect is observed for the present adhesive [56], but this effect is small for the narrow band of $R$-ratio tested. It is decided to describe the fatigue crack growth rates by $\Delta K$ [51]. Different other approaches to describe fatigue crack growth are presented by Pascoe et al. [40], but it is out of the scope to investigate this further.

In terms of constitutive properties and fracture toughness the adhesive is comparable to epoxy resins in the published literature [56, 57, 58, 59], but the exact properties of the adhesive used in the present work is confidential. From the DCB test it is found that the crack growth rates of the adhesive is comparable to those of epoxy resins [56, 60, 61, 62, 63, 57, 58, 59, 64], especially those tested in $[56,57,58,59]$.

\section{Experimental demonstration: Residual stress determination}

Solidification of the vinylester adhesive during curing is an exo-thermal process. The adhesive heats up, shrinks and builds up tensile residual stresses caused by the constraining effect from the laminates since the adhesive cannot freely contract. The procedure to measure the residual stress using the bilayer specimen is summarized:

- Manufacture sandwich specimen of two laminates bonded by adhesive.

- Peel-off one of the laminates, and measure curvature and geometry of the bi-layer specimen.

- Calculate residual stress through misfit stress from equation 7 and equation 8. 
The adhesive and laminates are manufactured under laboratory conditions. Two laminates of uni-directional glass fiber reinforced polyester are cast using VARTM. The laminates are post cured and placed in a fixture where a foam spacer is placed along the edges to control the adhesive thickness to be $8 \mathrm{~mm}$. One of the laminates are covered by a thin foil to create a weak adhesive/laminate interface. The adhesive is injected through a $10 \mathrm{~mm}$ hole in the middle of the plate and cured.

After post curing of the adhesive, the plate is cut into 13 specimens of length $500 \mathrm{~mm}$ and one of the laminates is peeled off using the thin foil since a weak plane enables separation. Removing one of the laminates cause the beam to bend due to tensile residual stresses in the adhesive. As indicated in Figure 8, the displacement of the top surface of the 13 beams is measured at 11 equal-spaced points using a dial gauge (type, Mitutoyo with ID-U1025). The laminate thickness, $h_{1}^{*}$ and adhesive thickness, $h_{2}^{*}$ of the bi-layer specimen are measured using a caliper in an optical microscope. Using equation 7, the average misfit stress, $\sigma_{T}$ of the 13 curvature specimens is determined and presented non-dimensionally as misfit strain: $\epsilon_{T}=-0.00218 \pm 0.00013$ [44]. The misfit stress is used to determine the residual stress, $\sigma_{r}$ at the various positions along the blade using equation 8 .

The residual stress in the adhesive, for each combination of measured $\alpha(y, z)$ and $h_{1}(y, z) / h_{2}(y)$ at each tunneling crack location in the blade section, is presented in Figure 15. Here, the residual stress is normalised by the maximum mechanical stress, $\sigma_{m}^{\max }$ that is introduced by equation 14 and Figure 10. The trend is that closest to the blade root (small $y$ ) the residual stresses are highest, which is attributed $h_{1} / h_{2}$ increasing towards the 


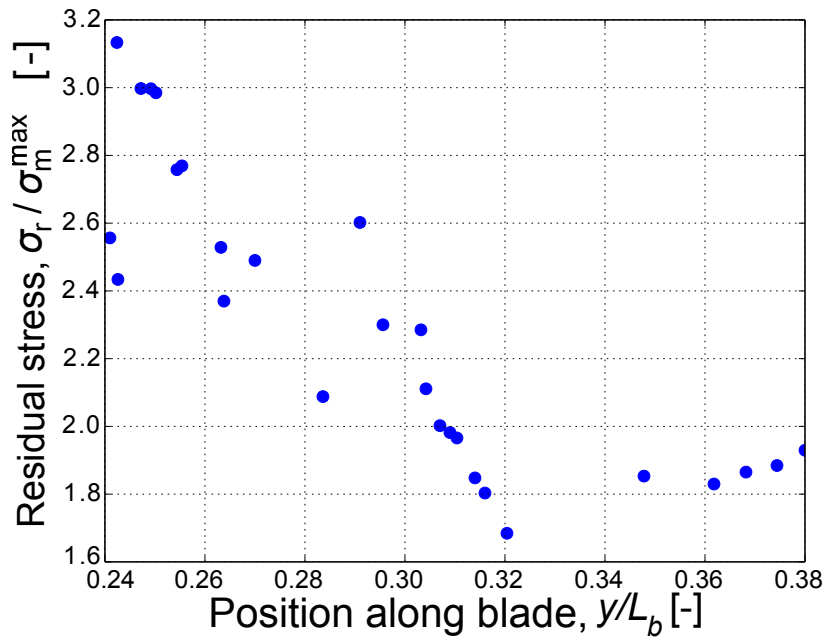

Figure 15: Normalised residual stress in the adhesive of the generic research blade at each tunneling crack position along the blade length.

blade root according to Figure 12. Note, $\sigma_{r}$ is large in comparison with $\sigma_{m}^{\max }$, especially closest to the blade root where the laminates are thick.

\section{Experimental demonstration: Modelling of tunneling cracks}

Curves for energy release rate, determined by the tunneling crack tool, are presented in Figure 16 including the corresponding "Experimental points" that are calculated based on data from the generic research blade test $(\alpha, \beta=$ $\left.\alpha / 4, h_{1} / h_{2}\right)$. The "Experimental points" are determined for each tunneling crack configuration $\left(z=a_{i}\left(N_{i}\right)\right)$ according to Figure 3. Thus, $\alpha$ and $h_{1} / h_{2}$ are determined for each crack tip location and based on linear interpolation between the curves in Figure 16, the energy release rate can then be read off for each point.

Ply drops in both the $y$ - and $z$-direction of the blade joint complicates the tunneling crack analysis. However, it is impractical to define a single finite 


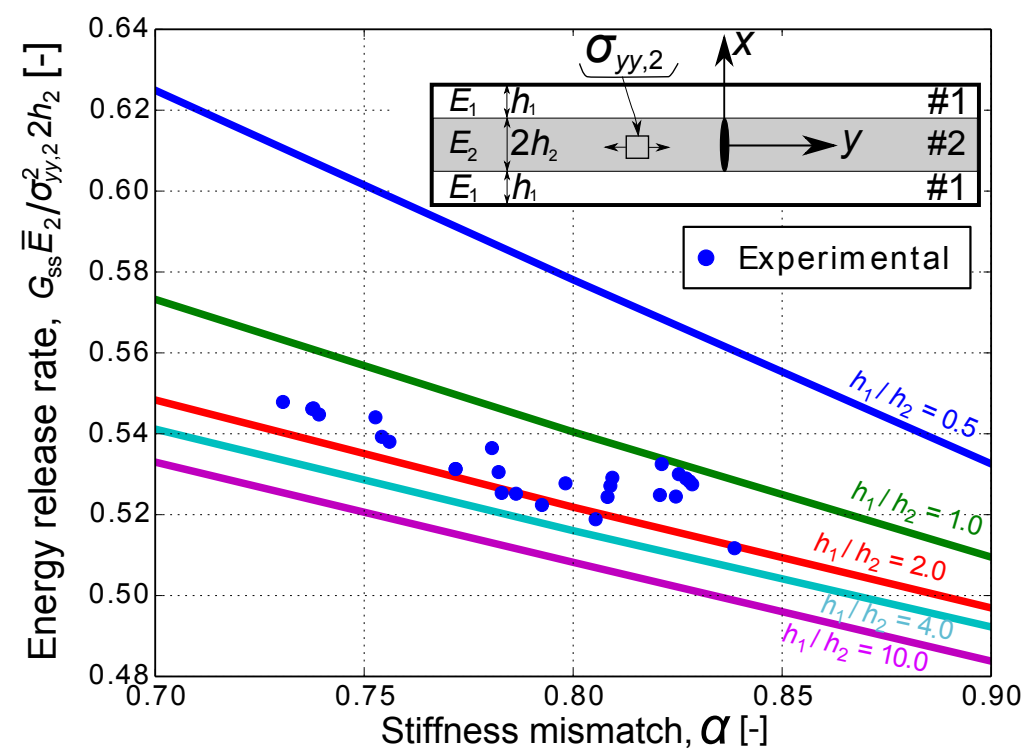

Figure 16: Results from tunneling crack bi-layer FE model with $\beta=\alpha / 4$ (part of Figure 9). "Experimental points" are calculated for each tunneling crack configuration.

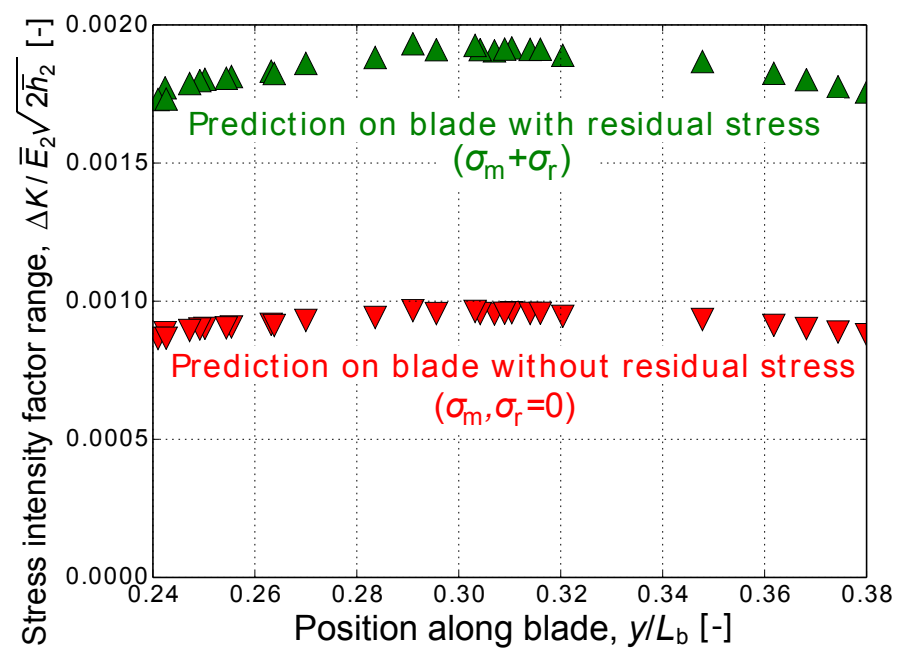

Figure 17: Prediction of $\Delta K$ based on data measured on the full scale blade joint at each tunneling crack position along blade length. $\Delta K$ is normalised by the plane strain modulus of the adhesive, $\bar{E}_{2}$ and by the average thickness of the adhesive measured on the generic blade section, $2 \bar{h}_{2}$. 
element model, e.g. with 5-12 different layers, for each crack observed and change the laminate stacking sequence for each crack analysed. Instead, the tunneling crack tool is made generic thus it can handle a series of isolated tunneling cracks and be applied to other blade joints as well. Therefore, the thickness ratio, $h_{1} / h_{2}$ and the average laminate stiffness are interpolated linearly in $y$ - and $z$-directions based on the actual crack tip location in the joint.

$\Delta K$ is determined based on equation 12 and presented in Figure 17 withand without including the magnitude of residual stress, $\sigma_{r} . \Delta K$ varies only moderately along $y$, being highest for $y / L_{b} \approx 0.30$. The inclusion of residual stresses doubles $\Delta K$ since the $R$-ratio changes from $R=-1$ to $R \approx 0.4$, see Figure 10 and Figure 17.

\section{Experimental demonstration: Inspection of cracks in full scale blade test}

The crack length, measured by a caliper on the trailing-edge joint, for each tunneling crack is presented in Figure 18 and Figure 19 for the number of cycles where the test of the generic research blade is paused for inspection. The $a-N$ measurements in Figure 19 are fitted with a straight line for each crack and the slopes $(d a / d N)$ are presented in Figure 20.

\section{Experimental demonstration: Prediction of fatigue crack gro- wth rates on the blade joint}

Tunneling crack growth rates are predicted using the approach in Figure 4 and presented in Figure 20 together with the measured crack growth rates 


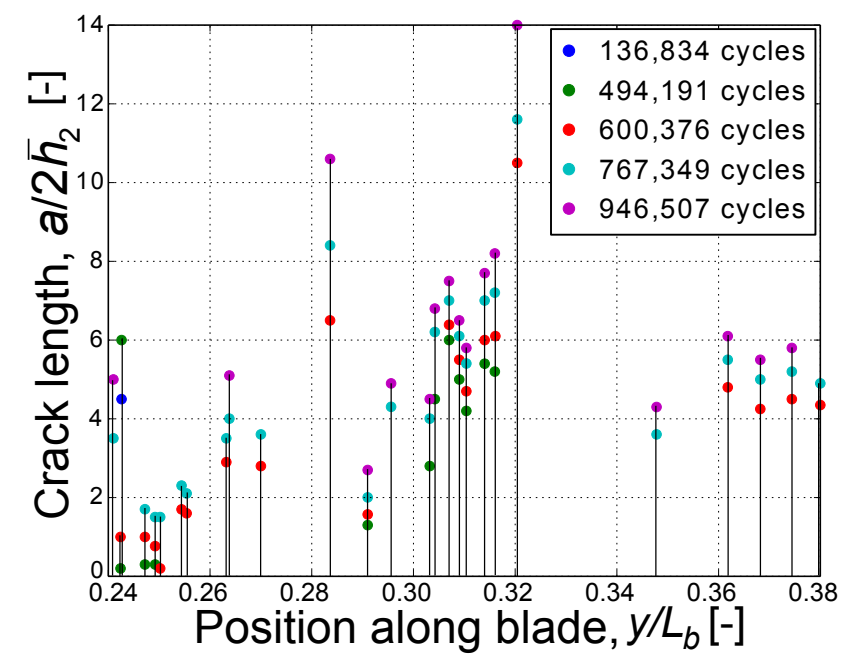

Figure 18: Normalised crack length, $a / 2 \bar{h}_{2}$ measured along blade length, $y$.

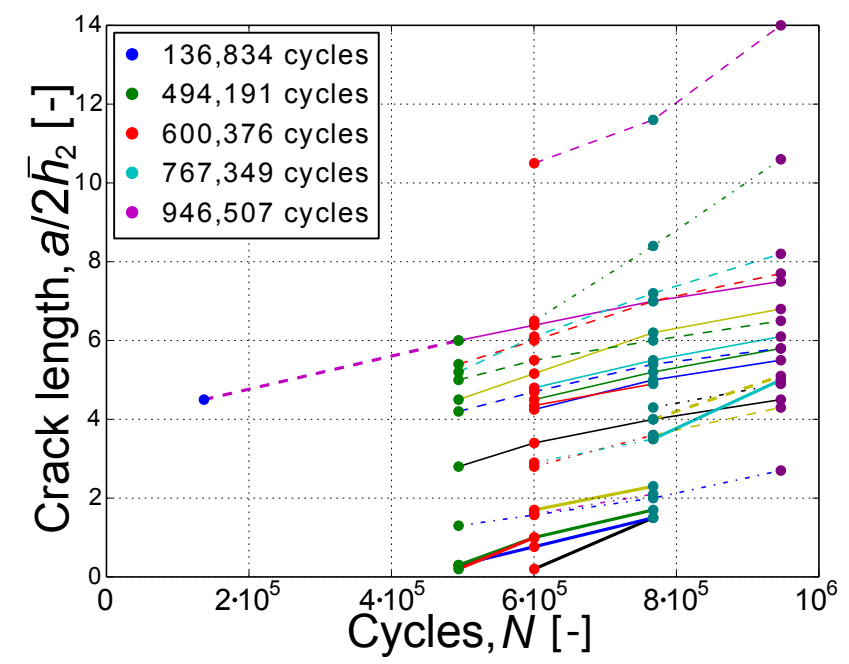

Figure 19: Normalised crack length, $a / 2 \bar{h}_{2}$ for cycles, $N$ measured on blade. 
on the trailing-edge joint from the test of the generic research blade. The predicted crack growth rates varies relative to crack location $(y, z)$ due to the variations in; $\alpha, h_{1} / h_{2}, \Delta \sigma_{m}$ and $\sigma_{r}$. However, this variation is small meaning that the state of each individual tunneling crack is similar. Also, the crack growth rates, measured individually for each tunneling crack, in the blade are similar, which can be explained by the small variations in load levels and geometry along the blade section (AoI).

The crack growth rates predicted on the blade joint falls above and below the crack growth rates measured on the blade. The crack growth rates predicted without including residual stress are closest to the crack growth rates measured on the blade.

\section{Discussion}

The crack-to-crack variation for the $d a / d N$ predictions in Figure 20 is small since the variation of the mechanical stress and the energy release rate for each crack in Figure 16 is small: $\left(\bar{E}_{2} G_{s s}\right) /\left(\sigma_{y y, 2}^{2} 2 h_{2}\right) \approx 0.53 \pm 0.02$. This

suggests that a future approximate approach is to use; $\left(\bar{E}_{2} G_{s s}\right) /\left(\sigma_{y y, 2}^{2} 2 h_{2}\right) \approx$ 0.5 for all tunneling cracks in the blade, which will simplify the modelling significantly. The effect of misfit stress, $\sigma_{T}$ is significant since the inclusion of residual stress doubles $\Delta K$ as shown in Figure 17.

The DCB- and bi-layer test specimens are manufactured under process conditions in the laboratory that are different from the manufacturing of the generic research blade. This difference in manufacturing process is an uncertainty in the cyclic crack growth prediction on the blade joint.

Another explanation for the deviation between blade prediction and ac- 


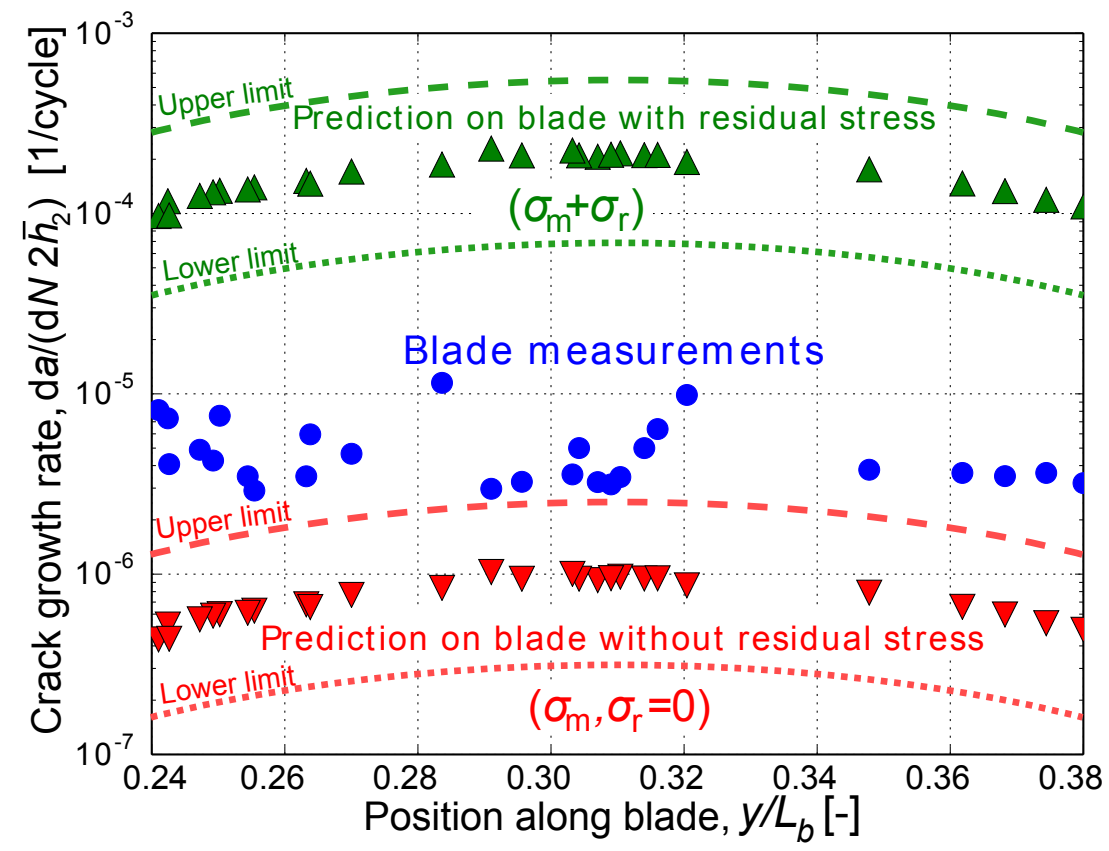

Figure 20: Comparison of predicted crack growth rates (triangles) with the crack growth rates measured (circles) on the full scale blade joint. Dashed lines indicate the upper limits and dotted lines the lower limits for the uncertainty of the predictions based on Figure 14 since the main uncertainty comes from the measured Paris law for the adhesive. Note, $d a / d N$ are normalised by the average thickness of the adhesive measured on the blade section, $2 \bar{h}_{2}$. 
tual blade measurements could be time dependency of the adhesive (stress relaxation, creep, visco-elasticity), which is unknown. The time scale for the laboratory tests of the bi-layer specimens is in the order of a few weeks whereas the generic full scale research blade is tested over several months. The time scale may influence the level of residual stress, which again affects the $R$-ratio, $\Delta K$ and finally the $d a / d N$ prediction. The effect of stress relaxation in the adhesive in the duration of the full scale blade test is unknown. The crack growth rates determined for the tunneling cracks including residual stress must therefore be seen as an upper bound. On the other hand, the crack growth rates predicted without residual stress should be seen as a lower bound if all residual stresses are relaxed during the fatigue test.

Multiple cracking of the adhesive is an other stress relaxing process especially if the crack spacing is small. The tunneling cracks can with good accuracy be modelled without including interaction between the cracks since the crack spacing and the stiffness of the substrates are large $(0.72 \leq \alpha \leq$ 0.84) $[23,24]$. Crack interaction is only relevant for very compliant substrates [24]. The 27 cracks distributed over the length of the blade section $\left(0.24 \leq y / L_{b} \leq 0.38\right)$ gives a normalised inverse average crack spacing of $2 \bar{h}_{2} / \bar{L}_{c}=0.038$, where $\bar{L}_{c}$ is the average crack spacing. This number $(0.038)$ and stiffness mismatch $(0.72 \leq \alpha \leq 0.84)$, according to Fig. 5 in Ho and Suo [24], means that crack interaction is insignificant for the present case.

\subsection{Tunneling crack model assumption}

It is appropriate to investigate whether the approach of averaging the stiffness has a significant effect on the tunneling crack energy release rate since the layers closest to the adhesive is a few number of biaxial layers that 
are more compliant than the uni-directional layers. The layer closest to the adhesive, called buffer-layer, is the most important layer since it is well known that the stiffness and thickness of this layer gives the primary constraining effect of the tunneling crack [31].

The effect of buffer layer is tested using a tri-layer tunneling crack FE model. A biaxial layer is added to the existing uni-directional laminate, which decreases the overall average stiffness ratio to $\alpha_{\text {ave }}=0.80$ from $\alpha_{U D}=0.85$ since the added biax-to-adhesive stiffness ratio is $\alpha_{\text {biax }}=0.54$.

Modelling the problem using the average stiffness instead of the actual stiffnesses of the individual layers gave an energy release rate that was approx. $4 \%$ higher, which is acceptable for the present application. It is concluded that the energy release rate is relatively insensitive to specific layup configurations for the present case since the uni-directional layers are relatively stiff. This is also illustrated by the small variations for the experimental data in Figure 16. Thus, from a practical point of modelling the use of average stiffness is reasonably.

\subsection{Tunneling cracks in full scale blade section}

In a full scale blade test many factors play a role on the state of the tunneling crack mechanism. One important factor is the assumption that loading is pure tensile in the trailing-edge, see $\epsilon_{y y}$ in Figure 1. Thus, the cracks in the adhesive are assumed to propagate under pure mode-I conditions, which is reasonably to assume in a homogeneous material. The mode-I dominance is supported by the image in Figure 2 of the tunneling crack that is perpendicular to the laminate. However, it is not measured whether the trailing-edge joint is loaded in shear as well e.g. caused by large rotations/displacements 
("pumping effect") of the trailing-edge balsa panel [65]. Measuring mixed mode effects on the tunneling cracks may require additional strain gauges mounted during the blade test. Models for shear loaded tunneling cracks (oblique cracks) are available in the literature $[24,66]$.

The measured crack lengths vary significantly along the length of the blade. The two cracks with the largest crack growth rates are found in the highest loaded region. The different crack lengths measured may be a result of the different times/cycles to crack initiation along the blade length $(y)$. The initiation is governed by pre-exising defects, but the exact time (load cycle number) of crack initiation is unknown. For the shortest cracks measured, see Figure 19, the effect of crack length on energy release rate could be accounted for using 3D FE simulations [34, 26]. However, for large elastic mismatch this transient effect is small [35].

\subsection{Proposed extensions of the present work}

The effect of residual stress on $R$-ratio and Paris law parameters is not well documented in the literature for polymeric materials. Further work for the adhesive loaded cyclic by different residual stress magnitudes and $R$-ratio including different models for fitting the crack growth rates is proposed as a future study $[53,40]$.

The tunneling crack tool can be extended to account for delamination during the tunneling process $[67,25,19]$ or expanded to handle gel coat channeling cracks in wind turbine blade surfaces during cyclic loading [68]. It may also be applied to tunneling cracks in grid-scored balsa/foam panels used in wind turbine blades, where the crack tunnels through the resin filled grid-scores [65]. The generic tool is demonstrated on a trailing-edge adhesive 
joint, but could be applied to the leading-edge- or web joints as well.

\section{Conclusion}

The parameters for the mode-I Paris law for the adhesive, measured by the cyclic moment-loaded DCB specimen, was found to be comparable to those published for epoxy resin systems. The energy release rate of a tunneling crack is relatively unaffected by substrate thickness when the substrate

stiffness is large. Furthermore, the energy release rate of a tunneling crack is relatively insensitive to specific layup near the adhesive since the stiffness of the primary uni-directional laminate is high.

The crack growth rates predicted for tunneling cracks in a wind turbine blade trailing-edge joint were found to agree well with the crack growth rates measured on a full scale test blade. This suggests that the tunneling crack tool can predict crack growth rates for tunneling cracks in a wind turbine blade trailing-edge joint within acceptable accuracy.

\section{Acknowledgements}

Acknowledgements to the LM Wind Power lab for help manufacturing the test specimens used for the bi-layer tests and the cyclic DCB tests. Thanks to Jan Sjølin at DTU Wind Energy for help testing the DCB specimens. Also, thanks to the test engineers and -technicians at LM Wind Power for help with the measurements during the full scale blade test. This research was supported by the Danish Centre for Composite Structure and Materials for Wind Turbines (DCCSM), grant no. 0603-00301B, from Innovation Fund 
Denmark. This research was also supported by grant no. 4135-00010B from Innovation Fund Denmark.

\section{References}

[1] DNV GL, DNVGL-ST-0376 Standard - Rotor blades for wind turbines, Tech. Rep. December, DNV GL (2015).

[2] F. M. Jensen, B. G. Falzon, J. Ankersen, H. Stang, Structural testing and numerical simulation of a $34 \mathrm{~m}$ composite wind turbine blade, Composite Structures 76 (1-2) (2006) 52-61. doi:10.1016/j.compstruct.2006.06.008.

[3] L. C. T. Overgaard, E. Lund, O. T. Thomsen, Structural collapse of a wind turbine blade. Part A: Static test and equivalent single layered models, Composites Part A: Applied Science and Manufacturing 41 (2) (2010) 257-270. doi:10.1016/j.compositesa.2009.10.011.

URL http://dx.doi.org/10.1016/j.compositesa.2009.10.011

[4] J. Yang, C. Peng, J. Xiao, J. Zeng, S. Xing, J. Jin, H. Deng, Structural investigation of composite wind turbine blade considering structural collapse in full-scale static tests, Composite Structures 97 (2013) 15-29. doi:10.1016/j.compstruct.2012.10.055.

URL http://dx.doi.org/10.1016/j.compstruct.2012.10.055

[5] H. F. Zhou, H. Y. Dou, L. Z. Qin, Y. Chen, Y. Q. Ni, J. M. Ko, A review of full-scale structural testing of wind turbine blades, Renewable and Sustainable Energy Reviews 33 (2014) 177-187. doi:10.1016/j.rser.2014.01.087. 
[6] X. Chen, W. Zhao, X. L. Zhao, J. Z. Xu, Preliminary failure investigation of a $52.3 \mathrm{~m}$ glass/epoxy composite wind turbine blade, Engineering Failure Analysis 44 (11) (2014) 345-350. doi:10.1016/j.engfailanal.2014.05.024.

URL http://dx.doi.org/10.1016/j.engfailanal.2014.05.024

[7] X. Chen, X. Zhao, X. Jianzhong, Revisiting the structural collapse of a $52.3 \mathrm{~m}$ composite wind turbine blade in a full-scale bending test, Wind Energy 20 (6) (2017) 1111-1127.

[8] C. Kong, T. Kim, D. Han, Y. Sugiyama, Investigation of fatigue life for a medium scale composite wind turbine blade, International Journal of Fatigue 28 (10 SPEC. ISS.) (2006) 1382-1388. doi:10.1016/j.ijfatigue.2006.02.034.

[9] X. Liu, Dynamic Response Analysis of the Blade of Horizontal Axis Wind Turbines, Journal of Mechanical Engineering 46 (12) (2010) 128. doi:10.3901/JME.2010.12.128.

[10] K. K. Jin, M. Ghulam, J. H. Kim, S. K. Ha, B. Lopez, A. Gorostidi, International Conferences on Composite Materials, in: Life Prediction of Wind Turbine Blades, 2009, pp. 1-12.

[11] D. Salimi-Majd, V. Azimzadeh, B. Mohammadi, Loading Analysis of Composite Wind Turbine Blade for Fatigue Life Prediction of Adhesively Bonded Root Joint, Applied Composite Materials 22 (3) (2014) 269-287. doi:10.1007/s10443-014-9405-4. 
[12] S. Ataya, M. M. Ahmed, Damages of wind turbine blade trailing edge: Forms, location, and root causes, Engineering Failure Analysis 35 (2013) 480-488. doi:10.1016/j.engfailanal.2013.05.011.

URL http://linkinghub.elsevier.com/retrieve/pii/ S1350630713001878

[13] K. W. Garret, J. E. Bailey, Multiple transverse fracture in 90 crossply laminates of a glass fibre-reinforced polyester, Journal of Materials Science 12 (1977) 157-168.

[14] Y. Korczynskyj, J. G. Morley, Constrained cracking in cross-ply laminates, Journal of Materials Science 16 (1981) 1785-1795.

[15] J. A. Nairn, The Strain Energy Release Rate of Composite Microcracking: A Variational Approach, Journal of Composite Materials 23 (11) (1989) 1106-1129. doi:10.1177/002199838902301102.

URL http://jcm.sagepub.com/cgi/doi/10.1177/ 002199838902301102

[16] J. Varna, L. Berglund, Multiple transverse cracking and stiffness reduction in cross-ply laminates, Journal of Composites Technology and Research 13 (2) (1991) 97-106. doi:10.1520/CTR10213J.

URL http://www. scopus.com/inward/record.url?eid=2-s2. 0-0026171255\{\\&\}partnerID=tZOtx3y1

[17] R. Talreja, S. Yalvac, L. D. Yats, D. G. Wetters, Transverse cracking and stiffness reduction in cross ply laminates of different matrix toughness, Journal of Composite Materials 26 (11) (1992) 1644-1663. 
[18] J.-M. Berthelot, Transverse cracking and delamination in cross-ply glass-fiber and carbon-fiber reinforced plastic laminates: Static and fatigue loading, Applied Mechanics Reviews 56 (1) (2003) 111-147. doi:10.1115/1.1519557.

URL http://dx.doi.org/10.1115/1.1519557

[19] A. S. Suiker, N. a. Fleck, Modelling of fatigue crack tunneling and delamination in layered composites, Composites Part A: Applied Science and Manufacturing 37 (10) (2006) 1722-1733. doi:10.1016/j.compositesa.2005.09.006.

URL http://linkinghub.elsevier.com/retrieve/pii/ S1359835X05003751

[20] J. Varna, Modelling mechanical performance of damaged laminates, Journal of Composite Materials 47 (20-21) (2012) 2443-2474. doi:10.1177/0021998312469241.

URL http://jcm.sagepub.com/cgi/doi/10.1177/ 0021998312469241

[21] M. Quaresimin, A damage-based approach for the fatigue design of composite structures, IOP Conference Series: Materials Science and Engineering 139 (2016) 012006. doi:10.1088/1757-899X/139/1/012006. URL http://stacks.iop.org/1757-899X/139/i=1/a=012006?key= crossref .98da71596a191dfd02cdc2b30cfdd12d

[22] Z. Suo, Failure of brittle adhesive joints, Appl. Mech 43 (5) (1990) 275279 . 
[23] J. W. Hutchinson, Z. Suo, Mixed Mode Cracking in Layered Materials, Advances in Applied Mechanics 29 (1992) 63-191.

[24] S. Ho, Z. Suo, Tunneling cracks in constrained layers, Mem. ASME 60 (1993) 890-894.

[25] A. S. Suiker, N. a. Fleck, Crack tunneling and plane-strain delamination in layered solids, International Journal of Fracture 125 (1) (2004) 1-32. doi:10.1023/B:FRAC.0000021064.52949.e2.

URL http://link.springer.com/10.1023/B:FRAC.0000021064. 52949.e2

[26] J. Andersons, P. H. M. Timmermans, J. Modniks, Mechanics of tunnelling cracks in trilayer elastic materials in tension, International Journal of Fracture 148 (3) (2008) 233-241. doi:10.1007/s10704-008-9197-3.

URL http://link. springer.com/10.1007/s10704-008-9197-3

[27] H. Beom, X. Zhuo, C. Cui, Tunneling cracks in the adhesive layer of an orthotropic sandwich structure, International Journal of Engineering Science 63 (2013) 40-51. doi:10.1016/j.ijengsci.2012.11.001.

URL http://linkinghub.elsevier.com/retrieve/pii/ S0020722512001978

[28] M. Thouless, Crack Spacing in Brittle Films on Elastic Substrates, J. Am. Ceram. Soc. 73 (7) (1990) 2144-46.

[29] J. Beuth, Cracking of thin bonded films in residual tension, Int. J. Solid Structures 2 (13) (1992) 1657-1675. 
[30] J. J. Vlassak, Channel cracking in thin films on substrates of finite thickness, International Journal of Fracture 119/120 (1979) (2003) 299323. doi:10.1023/A:1024962825938.

[31] T. Y. Tsui, A. J. McKerrow, J. J. Vlassak, Constraint Effects on Thin Film Channel Cracking Behavior, Journal of Materials Research 20 (2005) 2266-2273. doi:10.1557/jmr.2005.0317.

[32] H. G. Beom, H. S. Jang, Effect of elastic constants on crack channeling in a thin film bonded to an orthotropic substrate, Archive of Applied Mechanics 83 (11) (2013) 1577-1589. doi:10.1007/s00419-013-0766-1.

URL http://link.springer.com/10.1007/s00419-013-0766-1

[33] T. Nakamura, S. M. Kamath, Three-dimensional effects in thin film fracture mechanics, Mechanics of Materials 13 (1) (1992) 67-77. doi:10.1016/0167-6636(92)90037-E.

URL http://linkinghub.elsevier.com/retrieve/pii/ $016766369290037 \mathrm{E}$

[34] Z. C. Xia, J. W. Hutchinson, Crack patterns in thin films, Journal of the Mechanics and Physics of Solids 48 (2000) 1107-1131.

[35] J. M. Ambrico, M. R. Begley, The role of initial flaw size, elastic compliance and plasticity in channel cracking of thin films, Thin Solid Films 419 (2002) 144-153. doi:10.1016/S0040-6090(02)00718-6.

[36] J. Dundurs, Edge-Bonded Dissimilar Orthogonal Elastic Wedges Under Normal and Shear Loading, Journal of Applied Mechanics 36 (3) (1969) $650-652$. 
[37] J. Parmigiani, M. Thouless, The effects of cohesive strength and toughness on mixed-mode delamination of beam-like geometries, Engineering Fracture Mechanics 74 (17) (2007) 2675-2699. doi:10.1016/j.engfracmech.2007.02.005.

URL http://linkinghub.elsevier.com/retrieve/pii/ S0013794407000677

[38] J. Dundurs, Effect of elastic constants on stress in a composite under plane deformation, Journal of Composite Materials 1 (1967) 310-322. doi:10.1177/002199836700100306.

[39] P. Paris, F. Erdogan, Closure to Discussions of A Critical Analysis of Crack Propagation Laws', Journal of Basic Engineering 85 (4) (1963) 534. doi:10.1115/1.3656903.

URL http://fluidsengineering.asmedigitalcollection.asme . org/article . aspx?articleid=1431540

[40] J. A. Pascoe, R. C. Alderliesten, R. Benedictus, Methods for the prediction of fatigue delamination growth in composites and adhesive bonds - A critical review, Engineering Fracture Mechanics 112-113 (2013) 72 96. doi:10.1016/j.engfracmech.2013.10.003.

URL http://dx.doi.org/10.1016/j.engfracmech.2013.10.003

[41] P. J. Withers, H. K. D. H. Bhadeshia, Residual stress part 1 - Measurement techniques, Materials Science and Technology 17 (4) (2001) 355-365. doi:10.1179/026708301101509980.

URL http://www.scopus.com/inward/record.url? 
eid=2-s2.0-0034923107\{\\&\}partner ID $=40\{\backslash \&\} \mathrm{md5}=$ 814 ec6ced08c67e3e5ac9d2ebc9027b2

[42] P. Withers, H. Bhadeshia, Residual stress. Part 2 Nature and origins, Materials Science and Technology 17 (4) (2001) 366-375. doi:10.1179/026708301101510087.

[43] P. J. Withers, M. Turski, L. Edwards, P. J. Bouchard, D. J. Buttle, Recent advances in residual stress measurement, International Journal of Pressure Vessels and Piping 85 (3) (2008) 118-127. doi:10.1016/j.ijpvp.2007.10.007.

[44] A. G. Evans, J. W. Hutchinson, The Thermomechanical Integrity of Thin Films and Multilayers, Acta metall. mater. 43 (7) (1995) 25072530.

[45] H. P. Langtangen, Python Scripting for Computational Science, 2nd Edition, Springer, 2008.

[46] H. P. Langtangen, A Primer on Scientific Programming with Python, 4th Edition, Springer, 2014.

[47] B. F. Sørensen, K. Jørgensen, T. K. Jacobsen, R. C. Østergaard, A general mixed mode fracture mechanics test specimen : The DCB-specimen loaded with uneven bending moments, Int J Fract 141 (2006) 163-176.

[48] B. F. Sørensen, L. P. Mikkelsen, R. C. Østergaard, S. Goutianos, From interface laws to composite behaviour, in: Interface Design of Polymer Matrix Composites Mechanics, Chemistry, Modelling and Manufacturing, Risø, 2007, pp. 55-74. 
[49] R. M. Jones, Mechanics of composite materials, 2nd Edition, Taylor and Francis, 1999.

[50] G. Irwin, D. Washington, Analysis of Stresses and Strains Near the End of a Crack Traversing a Plate, Journal of Applied Mechanics 24 (1957) $361-364$.

[51] C. Rans, R. Alderliesten, R. Benedictus, Misinterpreting the results: How similitude can improve our understanding of fatigue delamination growth, Composites Science and Technology 71 (2) (2011) 230-238. doi:10.1016/j.compscitech.2010.11.010.

[52] J. A. Nairn, P. Zoller, The Development of Residual Thermal Stresses in Amorphous and Semicrystalline Thermoplastic Matrix Composites, ASTM STP 937 (1987) 328-341.

[53] J. A. Nairn, Energy release rate analysis for adhesive and laminate double cantilever beam specimens emphasizing the effect of residual stresses, International Journal of Adhesion and Adhesives 20 (1999) 59-70.

[54] R. Stephens, A. Fatemi, R. R. Stephens, H. Fuchs, Metal fatigue in engineering, 2nd Edition, John Wiley \& Sons, Inc, 2001.

[55] J. W. Holmes, L. Liu, B. F. Sorensen, S. Wahlgren, Experimental approach for mixed-mode fatigue delamination crack growth with large-scale bridging in polymer composites, Journal of Composite Materials 48 (25) (2014) 3111-3128. doi:10.1177/0021998313507613.

[56] C. Kanchanomai, A. Thammaruechuc, Effects of stress ratio on fatigue crack growth of thermoset epoxy resin, Po- 
lymer Degradation and Stability 94 (10) (2009) 1772-1778. doi:10.1016/j.polymdegradstab.2009.06.012.

URL http://dx.doi.org/10.1016/j.polymdegradstab.2009.06. 012

[57] E. N. Brown, S. R. White, N. R. Sottos, Fatigue crack propagation in microcapsule-toughened epoxy, Journal of Materials Science 41 (19) (2006) 6266-6273. doi:10.1007/s10853-006-0512-y.

[58] A. Boonyapookana, K. Nagata, Y. Mutoh, Fatigue crack growth behavior of silica particulate reinforced epoxy resin composite, Composites Science and Technology 71 (8) (2011) 1124-1131. doi:10.1016/j.compscitech.2011.02.015.

URL http://dx.doi.org/10.1016/j.compscitech.2011.02.015

[59] M. H. Kothmann, R. Zeiler, A. Rios De Anda, A. Brückner, V. Altstädt, Fatigue crack propagation behaviour of epoxy resins modified with silica-nanoparticles, Polymer (United Kingdom) 60 (2015) 157-163. doi:10.1016/j.polymer.2015.01.036.

[60] S. A. Sutton, Fatigue crack propagation in an epoxy polymer, Engineering Fracture Mechanics 6 (3) (1974) 587-595. doi:10.1016/00137944(74)90015-0.

[61] R. A. Gledhill, A. J. Kinloch, S. Yamini, R. J. Young, Relationship between mechanical properties of and crack progogation in epoxy resin adhesives, Polymer 19 (5) (1978) 574-582. doi:10.1016/00323861(78)90285-9. 
[62] M. Dessureautt, J. Spelt, Observations of fatigue crack initiation and propagation in an epoxy adhesive, International Journal of Adhesion and Adhesives 17 (3) (1997) 183-195. doi:10.1016/S0143-7496(96)00044-9. URL http://www.sciencedirect.com/science/article/pii/ S0143749696000449

[63] J. Du, M. D. Thouless, A. F. Yee, Effects of rate on crack growth in a rubber-modified epoxy, Acta Materialia 48 (13) (2000) 3581-3592. doi:10.1016/S1359-6454(00)00110-5.

[64] A. Boonyapookana, A. Saengsai, S. Surapunt, K. Nagata, Y. Mutoh, Time dependent fatigue crack growth behavior of silica particle reinforced epoxy resin composite, International Journal of Fatigue 87 (2016) 288-293. doi:10.1016/j.ijfatigue.2016.02.013.

[65] S. Laustsen, E. Lund, L. Kühlmeier, O. T. Thomsen, Development of a high-fidelity experimental substructure test rig for grid-scored sandwich panels in wind turbine blades, Strain 50 (2) (2014) 111-131. doi:10.1111/str.12072.

[66] Z. Xia, J. W. Hutchinson, Mode II Fracture Toughness of a Brittle Adhesive Layer.pdf, Int. J. Solids Structures 31 (8) (1994) 1133-1148.

[67] K. Chan, M. He, J. Hutchinson, Cracking and stress redistribution in ceramic layered composites, Materials Science and Engineering A167 (1993) 57-64.

[68] H. Zhang, J. Jackman, Feasibility of Automatic Detection of Surface 
Cracks in Wind Turbine Blades, Wind Engineering 38 (6) (2014) 575586. 